\title{
Cryptocurrency adoption: current stage, opportunities, and open challenges
}

\author{
Redhwan Al-Amri ${ }^{1}$, Nur Haryani Zakaria ${ }^{2 *}$, Adib Habbal ${ }^{3}$ and Suhaidi Hassan ${ }^{4}$ \\ Research Scholar, School of Computing \& IT, Taylor's University, Malasysia ${ }^{1}$ \\ Senior Lecturer, School of Computing, Universiti Utara Malaysia, Malaysia ${ }^{2}$ \\ Associate Professor, Karabuk University, Turkey ${ }^{3}$ \\ Professor, School of Computing, Universiti Utara Malaysia, Malaysia ${ }^{4}$
}

Received: 13-September-2018; Revised: 16-January-2019; Accepted: 30-January-2019

(C)2019 Redhwan Al-Amri et al. This is an open access article distributed under the Creative Commons Attribution (CC BY) License, which permits unrestricted use, distribution, and reproduction in any medium, provided the original work is properly cited.

\begin{abstract}
Cryptocurrency is attracting the attention of academic and non-academic researchers as an alternative architecture of currency. Because of the growing of cryptocurrency research, it is essential to value the existing research of cryptocurrency and identify potential future research areas. This paper provides an up to date review of IS research on cryptocurrency adoption. In this paper, we conduct a systematic literature review to gather the previous research related to cryptocurrency adoption. The goal of this research is to identify the current research stage and open challenges for future studies in cryptocurrency adoption. Moreover, the paper presents a systematic literature review (SLR) of 25 research articles published on the adoption of cryptocurrency from 2014 to 2017. The results demonstrate that cryptocurrency adoption research has grown significantly throughout this period, and remains a fertile area for academic research. The results show that the cryptocurrency adoption literature can be classified according to three main classifications: qualitative research, quantitative research and others. The results of the SLR reveal that there is a lack of study focusing on the factors that are significantly influenced on the acceptance of cryptocurrency. Furthermore, there is also a lack of technology acceptance models used in addressing the issues. Research gap found is presented and discussed.
\end{abstract}

\section{Keywords}

Blockchain, Monetary decentralization, Technology adoption, Systematic literature review.

\section{Introduction}

As technology keeps on improving, consumers' demand for flexible, convenient, cost and timeefficient transaction continues to drive the evolution of payment platforms [1]. One of the latest and most promising digital inventions in the financial landscape is the evolution of the decentralized digital-currencies known as cryptocurrency and its online payment protocols built on a peer-to-peer network known as Blockchain [2]. Cryptocurrency is a virtual currency that is designed as an alternative to standard fiat currency, allowing consumers to execute digital payment for goods and services without the need for intermediaries [3]. In other words, it is a new form of digital currency platform grounded on a computer cryptography and decentralized network architecture [4], whose transactions records are stored on the blockchain public distributed ledger [5].

\footnotetext{
*Author for correspondence
}

Cryptocurrency exchanges for national fiat currencies over numerous of informal Internet-based exchanges [6].

In short, cryptocurrency is a completely decentralized currency without a central issuer [3]. Based on specialized open-source software, a set amount of cryptocurrency is given to users in exchange for specific contributions to the operation of the cryptocurrency system [4]. Consumers are able to transfer cryptocurrency among each other or use it to pay for goods and services, as long as there is merchants' acceptance. Cryptocurrency can also be traded in national currencies through several informal Internet-based exchanges [4].

In this research, a Systematic Literature Review (SLR) is performed to identify the carried-out research topics related to cryptocurrency adoption and models that have been used as well as the current adoption challenges that need to be overcome in future studies. 
Redhwan Al-Amri et al.

To accomplish this goal, systematic literature review was selected as the methodology to explore relevant papers in scientific databases and to draw a map of current cryptocurrency adoption research. The remaining of the paper is organized as follows.

Section two explains the study design. First, we briefly provide a background about cryptocurrency, and then describes the goal and research questions of the SLR followed by the research process. In section three, we present the classification achieved from the literature review as well as a summary of the previous related research conducted. In section four, we discuss the current gap in the research. Finally, in section five we provide conclusions as well as future research directions.

\section{Background of cryptocurrency}

Although digital currency concept has existed since 1980s, cryptocurrency was only utilized with the launching of Bitcoin as a decentralized cryptocurrency in 2009 using the Blockchain technology [7]. Blockchain was designed with the aim of creating a decentralized environment where transaction and data are not controlled by a thirdparty. Blockchain is a distributed database platform which preserves an incessantly growing list of data records which are verified by the mining nodes. The data is stored in a public ledger, containing information about each and every completed transaction [8]. Blockchain is a decentralized solution that operates without the need for third-party organization involvement. Blockchain shares all the information regarding each and every transaction ever conducted and makes it available to all nodes [8]. This characteristic makes the Blockchain more transparent than traditional centralized transactions involving a third-party organization. Furthermore, as a degree of security for nodes to confirm the transaction made, notes in Blockchain are all anonymous [8]. The whole process performed by each node is known as mining, every time a block is verified, and the miner receives a reward amount as for his /her participation in mining. Miners can be anyone as it is an open community of users interested in checking and validating new cryptocurrency transaction records [4]. The first miner to successfully validate a new transaction obtains the reward.

Cryptocurrency technology moved the financial market one extra step towards the future by decentralizing the currency and releasing it from the hierarchical power structures. As a substitute, consumers and organizations perform transactions digitally on a peer-to-peer network [1].
Cryptocurrency allows consumers to exchange value electronically independently without the need for other authorities nor on intermediaries to facilitate the process. Generally, the whole process of cryptocurrency transaction undergoes the concept of encryption algorithm theory, solving to create a unique hash values that are finite in numbers. Using a network of computer nodes to verify transactions, consumers are capable of trading and exchanging hushes just like a standard fiat money [1].

\section{Methodology}

This paper's goal is to identify the current stage of cryptocurrency adoption and the models that have been used as well as the adoption challenges that need to be addressed in future studies. Firstly, we performed an SLR to gather used cases of the cryptocurrency adoption and to gather evidence from the literature regarding the current stage of adoption, the models used and future potential factors to be addressed to improve the adoption rate of the cryptocurrency among users. To accomplish the goal of our SLR, research questions were formulated as follows:

RQ1: What research topics have been addressed in cryptocurrency adoption?

The SLR main research question is to highlight the existing research topics on cryptocurrency adoption. By gathering related papers from scientific databases, it would be possible to form a general understanding of cryptocurrency adoption research and identify the current research areas. Identifying the current research conducted on the adoption of cryptocurrency will significantly assist researchers in gaining a better understanding of the current stage of adoption, which will then carry the research on cryptocurrency adoption even further.

RQ2: What models have been used to carry out cryptocurrency adoption research?

Adoption models are mostly known for their relation to social aspects, system adoption, user attitudes and behavior towards new technology innovation. By reviewing all the relevant papers, it would be possible to create a summary of what have been done by previous researchers in this area as well as what models have been used to carry out the research. At the same time, reviewing the related models will make it easier to identify all the significant factors that influence the adoption of cryptocurrency.

\section{RQ3: What are the current gaps in cryptocurrency adoption?}

A systematic literature review provides an understanding of the existing research gaps. Identifying the research gaps will assist researchers in focusing their research on potential research areas. Highlighting the research gaps will provide an 
understanding of the research questions regarding the current cryptocurrency adoption.

RQ4: What are the directions for future research on the adoption of cryptocurrency?

Understanding the potential future research directions for cryptocurrency adoption is a consequence of RQ1-RQ3. Responding to this research question is helpful in the stage of determining where the research of cryptocurrency adoption should be directed and what factors need to be addressed.

\subsection{Search process}

To perform this study, guidelines on SLR given by Kitchenham [9] were followed. The keywords cryptocurrency adoption / acceptance was used to explore the listed digital libraries: IEEE Xplore; ACM Digital Library; SpringerLink; ScienceDirect; Google Scholar. A total number of 37 papers were gathered. In order to select which one of them to be intensely analyzed. Next, two exclusion stages were conducted, one is based on titles and the other is based on abstracts. Followed, papers regarding nonadoption aspects (e.g. papers focusing on security and legal issues or purely technical aspects of cryptocurrencies) were excluded. Finally, a total of 25 papers left, from which the information necessary were extracted to answer the research questions.

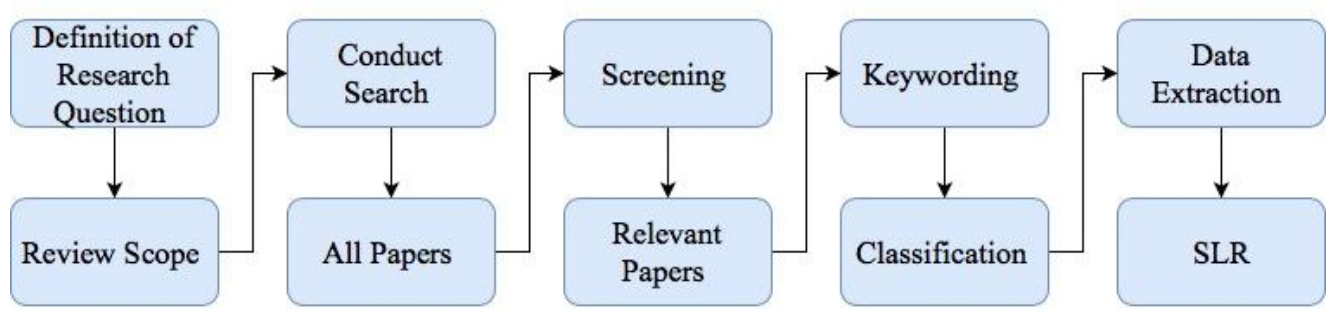

Figure 1 Systematic literature review search process [8]

Figure 1 illustrates the methodology used in conducting this SLR. At the first phase, papers were screened according to their titles and then papers with no relevance to the research topic were excluded. For instance, the search engine shows papers which are not related to the adoption of cryptocurrency. These papers were evidently out of the scope of this systematic literature review.

Nevertheless, in several cases, it was hard to decide the relevancy level of the papers based on the title. In these cases, papers were passed through the following stages for more reading process. In the following phase, we read the abstracts of each paper that passed the previous phase. Furthermore, a particular inclusion and exclusion criteria were utilized to screen each paper. Then, we decided to exclude the subsequent types of papers: (1) papers that had addresses cryptocurrency from other aspects than adoption and (2) papers that were duplicates. Papers that passed the exclusion criteria, was considered a focus on cryptocurrency adoption; therefore, we decided to include it in the next screening stage.

The following stage in this systematic literature review is Keywords. Keywords used includes (Adoption, Adopters, Acceptance, Usage, Use, Usability, Choice, Choosing, Motivation, Intention, Perception, Understanding, Perceived). Keywords filtering were conducted in two stages. The first stage involved reading the abstract and identifying keywords and concepts that reflected the contribution of the research [10]. The second stage was to build a higher level of understanding based on these keywords. Keywords were used to cluster and form categories in the systematic literature review. After the categories had been clustered, comes the process of reading all the selected papers. This led to an SLR of clustered categories formed from all the relevant studies related to the research topic.

\section{Results in cryptocurrency adoption 4.1Classification results}

In this section, twenty-five articles were identified in which all of them were published within the past four years. This classification will involve categorizing the results based on research approach taken (qualitative, quantitative, mixed method and other). Based on these results, it is evident that cryptocurrency adoption research has continued to increase over the years of study. The results extracted from the analyzed papers were reported, organized to answer the research question (i.e.: RQ1 and RQ2). Discussion on the results will follow in Section 4. The results answering RQ1 and RQ2 are presented below in a form of discussion and summary tables. Precisely, for each study, we report: the category in which we classified the study, the reference to the 
Redhwan Al-Amri et al.

study in the bibliography, the area of research, model, and methodology used and the country.

4.1.1 Qualitative research

Qualitative research is the first category of this classification. In this category, authors used the interview as a method to carry out their research. A research conducted by [11], examined the cryptocurrency as a promising type of payment platform by conducting an inductive and investigative interview with 13 consumers in three separate categories to determine the usability, usefulness, and subjectivity norm effects on consumers' intention towards the adoption of cryptocurrency. Using Technology Acceptance Model (TAM) that focuses on perceived ease of use, perceived usefulness, and subjective norms, the authors have come up with results that perceived ease of use is considered low by most of stakeholders and perceived usefulness is fluctuating based on consumers' category. The concept of cryptocurrency as a promising payment platform with potential in the future is confirmed by all the interviewees. However, there are some boundaries related to this study. First, only 13 individuals were interviewed, which makes generalization difficult, whereas, targeting a bigger population through quantitative research is highly recommended to make generalization possible. Second, the results might be biased as one-third of the interviewees is working for Bitcoin exchanges. Thus, they might be seeing cryptocurrencies as too positive and promising. Furthermore, Corina and Iris in their research [2], explores the consumers' motive and knowledge about cryptocurrency, by conducting interviews with 20 bitcoin consumers in Malaysia focusing on their experience and trust challenges while using the system. Results indicate that the majority of participants are using bitcoins for storing as a value for speculative investment or savings' protection. In this research, the authors advance the HCI theories on trust by classifying bitcoin's main characteristics in addition to their influence on consumers' trust, such as decentralization, upregulation, embedded expertise, reputation, as well as transactions' transparency, low cost, and easiness to complete the tasks. The research outcome leads to many design implications that would support bitcoin consumers to build and increases their overall trust in each other, together with support for the transparency of two-way transactions, tools for materializing trust, and tools for supporting reversible transactions.

Another research conducted on consumers' experience with cryptocurrency technology involved interviewing (9) Bitcoin users [12]. The researcher emphasized on the consumers' motive toward owning bitcoins by highlighting three types of motivation, namely as bitcoin's predicted role in monetary revolution, consumers' power increase, and the perception of currency's a real value. The results emphasize on the importance that consumer's motivation toward adoption cryptocurrency as well as the potential of blockchain technology in the transformation of global financial institutions using the democratizing platform. Finally, as for future potential direction, the authors recommend exploring the materiality of cryptocurrency and the feasibility of technological intervention supporting it. A recent research conducted on the cryptocurrency consumers' level of usability as well as experienced by some authors from Dalhousie University in Canada [6]. The authors investigate the factors influencing the widespread usage of bitcoin and whether usability effecting beginner consumers' adoption for bitcoin. Interviews were carried out to investigate the participants' perception towards using bitcoin. The research finding helps in clarifying how the conceptual map of bitcoin, financial literacy and usability of the product contributes to the overall consumers' experience of the tasks performed. As for future work, the authors are suggesting that the attention should continue on beginners or infrequent consumers of cryptocurrency, however the study should also accommodate a bigger variety of participants, particularly with varying age, technical background, and financial literacy.

A study conducted by [13] to understand the factors influence distinguished organization adopters of cryptocurrency from non-adopters by comparing their level of IT-readiness, innovativeness and social media involvement. As highlighted by the authors, organization adoption for cryptocurrency is classified as more important than consumer adoption, since consumers are not able to use cryptocurrency if organizations do not accept it as a method of payment. The authors employ the diffusion of innovations (DOI) theory to conduct the analysis and measure the innovation's actual diffusion. Thus, organizations can use these results to compare themselves to bitcoin adopters and non-adopters to identify their own level of readiness to adopt bitcoins. The author emphasizes that future research should extrapolate future cryptocurrency diffusion and adoption and survey companies directly as to why they adopted cryptocurrency, which will increase the overall understanding of how an innovation proceeds through the adoption lifecycle. 
Table 1 Qualitative research

\begin{tabular}{|c|c|c|c|c|c|}
\hline Category & Paper & Area of research & Model & $\begin{array}{l}\text { Methodology } \\
\text { used }\end{array}$ & Country \\
\hline \multirow{5}{*}{$\begin{array}{l}\text { Qualitative } \\
\text { Research }\end{array}$} & {$[11]$} & $\begin{array}{l}\text { User adoption and future } \\
\text { potential of bitcoin }\end{array}$ & TAM & Interview & Germany \\
\hline & {$[2]$} & $\begin{array}{l}\text { Challenges and opportunities of } \\
\text { bitcoin users }\end{array}$ & $\begin{array}{l}\text { HCI Theory } \\
\text { on Trust }\end{array}$ & Interview & $\begin{array}{l}\text { UK } \\
\text { Malaysia }\end{array}$ \\
\hline & [12] & $\begin{array}{l}\text { Exploring motivations among } \\
\text { bitcoin users }\end{array}$ & $\begin{array}{l}\text { HCI Theory } \\
\text { on Trust }\end{array}$ & Interview & $\begin{array}{l}\text { UK } \\
\text { Malaysia }\end{array}$ \\
\hline & [6] & $\begin{array}{l}\text { Determining the usability of } \\
\text { bitcoin for beginners }\end{array}$ & - & Interview & Canada \\
\hline & [13] & $\begin{array}{l}\text { Adopters of bitcoin from non- } \\
\text { adopters }\end{array}$ & DIT & Interview & USA \\
\hline
\end{tabular}

4.1.2 Quantitative research

Quantitative research is the second category of this classification. In this category, authors used the survey as a method to carry out their research. The consumer's level of usage acceptance of cryptocurrency by employing the unified theory of acceptance and use of technology (UTAUT) to build his hypotheses on consumers' usage acceptance has been addressed [14]. The author validated his hypothesis via a survey of (100) participants and the findings imply that performance expectancy and effort expectancy both are considered significant factors influencing the acceptance of cryptocurrency. As for future work, the author recommended extending the population of the study to cover banking industry, stock brokerages, foreign currency exchanges and online merchants. Additionally, the author is recommending a research on determining the factors that influence the value of cryptocurrency as well as conducting a research to determine the effect of spending cryptocurrency in countries where the domestic currency is less valuable than a foreign currency.

Another study demonstrates that news reporting (as information) is a vital factor for determining the level of adoption and pricing for bitcoin [15]. This study reflects the first look at the process of information used as part of speculation in the decision-making process as well as how such information might be compatible within a trust model. The authors conclude the research by proposing a trust model for Bitcoin speculators' use of news reporting as an information source. Results were obtained through a survey questionnaire that was distributed among bitcoin consumers. As for future work, the authors recommended a further examination in two key areas. Firstly, whether bias news might have an impact in the trust model. Secondly, how different features of news stories impact upon those biases. Further work will suggest extending the investigation beyond news reporting and include social discourse as another information source.
Integrating both the technology acceptance model (TAM) and the innovation diffusion theory (IDT), [16] examined the factors that are associated with a decision to adopt bitcoin as a method of financial exchange. By utilizing structural equation modeling and the partial least squares method, the authors were able to develop and validate their research model through an international study that survey of 121 participants of cryptocurrency globally. The findings of the study indicate that ease of use is proven to have a significant positive effect on consumers' intention to use bitcoin while, visibility and compatibility were found to have a statistically positive impact. Despite the fact that the study offers a set of interesting finding there is still some limitation associated with the study that need to be addressed. These limitations include the sampling method employed as well as the sample size. As for future direction the authors recommend examining the factors and the model in different geographical setting and investigate the similarities and differences that may exist in the research findings.

At the same time, [17] utilized the technology acceptance model TAM to integrate several benefits and risks of bitcoin usage to develop the multidimensional constructs (perceived benefit and perceived risk model). The authors proposed an empirically tested theoretical framework that clarifies the usage of bitcoin as an online method of payment for legal purchases and fund transfers. Additionally, the authors identify some conceptual and methodological development potentialities to be integrated into the technology acceptance theories in the context of decentralized and sharing economy systems. This methodology has presented as significant in illustrating the vital determinants and barriers toward the usage of bitcoin among consumers. Nevertheless, there are still some drawbacks of this study that need to be overcome in future research. Firstly, the small population limits the robustness and generalization of the findings. 
Redhwan Al-Amri et al.

Additionally, the proposed model ignores other significant factors such as hedonic benefits, subjective norms, social factors, facilitating conditions, or trust that may have considerable influence on consumers' decisions towards adopting cryptocurrency.

Another research addressed the consumers' perception about bitcoin value was made by [18]. In this research, the authors examine the factors influencing the success of bitcoin value in Thailand and proposed a guide for self-reliance for effective business implementation. The population of this research consists of (121) participants via online surveys. The findings indicate four main factors affecting the success of bitcoin value which is the awareness and knowledge of cryptocurrency and the usefulness of cryptocurrency. The authors emphasize that future work should include educating the public on the benefits and usefulness of cryptocurrency as well as conducting training in applied bitcoin development. Furthermore, the authors believe that a higher perceived value will lead consumers to think that bitcoin is better than fiat currency. At the same time, the price can impact the perceptions of value.

Similarly, a different research done by [18] addressed the consumers' perception of Litecoin value. Within this study the author examines factors influencing the success of Litecoin value in Thailand and develops a guide for self- reliance for effective business implementation. The population of this research consists of (119) participants via online surveys. The effect of this study is shown in today's mining and trading results. An accurate reflection of real value and perceived values are revealed in today's markets. Yet, a higher perceived value will lead consumers to believe that Litecoin is better than bitcoin. Similarly, the price can impact the perceptions of value.

A research was conducted in the context of bitcoin adoption and price formation made by [19]. In this research, the authors conducted a survey on merchants who have adopted cryptocurrency globally by modeling the share of sales paid for with this alternative currency, using ordinary and Tobit regressions. Within the analysis, the authors examined how a country, customer, and organization characteristics interact with the percentage of sales attributed to bitcoin. The findings of the study highlighted that organization characteristic, payment approaches, consumer's knowledge about cryptocurrency and the size of both the official and unofficial economies are significant determinants in the success of cryptocurrency adoption. According to the authors, such results have a practical significance to those interested in trading and those seeking to understand the factors driving price fluctuation. Not only that, but it also helps merchants understand the circumstances for adopting cryptocurrency as a method of payment. As for future work, the authors believe that one of the main barriers in cryptocurrency widespread adoption is the legal status. Alongside this, there is huge confusion as legislators trying to determine cryptocurrency status for tax purposes, even within the European Union countries there is no standard method.

A research was performed to investigate the factors behind choosing a cryptocurrency by [20]. This research was conducted to address two main questions regarding to the bases on which online consumers decide to adopt cryptocurrency as well as the significant factors affecting cryptocurrency popularity and value. The study was carried out using an online survey to answer the question behind choosing a cryptocurrency. The findings reveal that currency name and logo plays a vital role affecting the consumers' decision in choosing a cryptocurrency to use and mine. Moreover, a mass of the participants indicates that ease of mining, privacy, and the cryptocurrency's value considers a significant factor to influence the intention to use or mine a cryptocurrency. The authors believe that in the future, researchers should include more questions in their studies about cryptocurrency to get a deeper understanding of cryptocurrency as well as investigating the consumer's perception regarding cryptocurrency especially in the Middle East region as this region still faces a shortage of significant involvement in crypto-currency.

Another research conducted in the digital currency trust was performed by [21]. The authors extend the theories of trust from e-commerce to incorporate cryptocurrencies. More specifically trust in business to consumer e-commerce transactions carried out using cryptocurrencies such as Bitcoin is explored. Assessing the validities of the proposed cryptocurrency trust model was the main contribution of this study. The findings support the validity of the role of the rate of adoption and reputation of cryptocurrency as part of situational normality. Finally, the authors highlighted the need for extending the research to confirm the findings in different settings using a different methodology and different cryptocurrency other than bitcoin.

In a different research addressing the use of bitcoin in light of financial crisis performed by [22]. The authors carried out the research using a survey within the Greek context to investigate questions such as 
whether the usage of cryptocurrency is widespread enough to lead to complete or partial disintermediation of monetary transactions, as well as whether consumers understand how the technology works and what are the risks associated with such alternative method of payment. The findings indicate that even though bitcoin end-users are somehow concerned about security issues associated with the use of cryptocurrency, they are nevertheless interested in its usage as a new business opportunity and bypassing limitations and obstacles such as capital controls. As for the future, the authors recommend investigating deeper into consumers' trust and risk perceptions and investigate whether these are similar or inherently different from the perceptions they hold towards fiat currencies.

Their research focuses on measuring the adoption and use of cryptocurrencies by consumers for payment purposes [23]. The authors carried out the research by conducting a survey with the aim to discover the consumers' payment preference from the Federal Reserve Bank of Boston. The research begun by providing preliminary empirical and econometric results that characterize the U.S. consumers' experience with bitcoin as well as other cryptocurrencies. Research findings emphasize that consumers' awareness, adoption, and usage of cryptocurrencies are correlated with different demographic and economic characteristics. The results indicate that a typical bitcoin owner is more probable to be a young, non-white male with lower education who is expecting to gain profit out of bitcoin, who has adopted other payment mechanisms, and his main responsibility is household shopping. The authors are suggesting investigating deeper into questions regarding the extreme view that cryptocurrencies are just speculative investment, particularly due to the relatively limited payments acceptance choices amongst the merchants.
In Germany, a study has been conducted on whether consumers' interest in cryptocurrencies is motivated by its attractiveness as an asset or as a method of payment for daily purposes, more precisely on the consumers' intentions to replace fiat currency into a cryptocurrency [24]. The findings present a solid indication that particularly uninformed consumers approaching cryptocurrencies are not primarily interested in it as an alternative transaction mechanism, instead they are seeking to participate in an alternative investment method. As for future direction, the authors suggest examining whether essential characteristics of financial markets also hold for bitcoin markets. Besides that, it is also recommended to extend the analysis by examining the potentials for inter-exchange arbitrage exists and the fact that behavioral biases such as herding control the bitcoin consumer decision-making.

Furthermore, in Korea some researchers conducted a study to examine the level in which bitcoin's consumers are depending on the speculative opportunities in the bitcoin marketplace and accordingly to validate bitcoin's competence against fiat currency [25]. The authors utilize model design by Dowd and Greenway's (1993) for currency acceptance and expresses that the reason behind bitcoin's incompetence as an alternative to fiat currency may be due to its low level of network effects. The study results recommend a new direction of survival for bitcoin or cryptocurrencies in general. By actively utilizing methods to attract consumers and forming a strong network, bitcoin and other cryptocurrencies may stand a better chance of overtaking the fiat currency. As stated by the authors, one of the possible directions for making additional contributions in the field of cryptocurrency adoption includes investigating more into the network effects of bitcoin.

Table 2 Quantitative research

\begin{tabular}{|c|c|c|c|c|c|}
\hline Category & Paper & Area of research & Model & $\begin{array}{l}\text { Methodology } \\
\text { used }\end{array}$ & Country \\
\hline & {$[14]$} & Acceptance of bitcoin & UTAUT & Survey & Colorado \\
\hline Quantitative & {$[15]$} & $\begin{array}{l}\text { Undermining speculative } \\
\text { cryptocurrency decisions }\end{array}$ & $\begin{array}{l}\text { Trust } \\
\text { Model }\end{array}$ & Survey & UK \\
\hline Research & [16] & $\begin{array}{l}\text { The diffusion and adoption of } \\
\text { bitcoin }\end{array}$ & $\begin{array}{l}\text { TAM } \\
\text { IDT }\end{array}$ & Survey & $\begin{array}{l}\text { Korea I } \\
\text { New } \\
\text { Zealand }\end{array}$ \\
\hline & {$[17]$} & $\begin{array}{l}\text { Perceived benefit and risk as } \\
\text { multidimensional determinants of } \\
\text { bitcoin use }\end{array}$ & TAM & Survey & $\begin{array}{l}\text { Germany/ } \\
\text { Austria }\end{array}$ \\
\hline & {$[18]$} & Thai perception on Litecoin value & - & Survey & Thailand \\
\hline & {$[18]$} & Thai perception on bitcoin value & - & Survey & Thailand \\
\hline & [19] & $\begin{array}{l}\text { Price fluctuations and the use of } \\
\text { bitcoin }\end{array}$ & - & Survey & UK \\
\hline
\end{tabular}


Redhwan Al-Amri et al.

\begin{tabular}{|c|c|c|c|c|}
\hline$[20]$ & $\begin{array}{lll}\text { Investigating factors } & \text { behind } \\
\text { choosing a cryptocurrency } & \end{array}$ & - & Survey & UAE \\
\hline$[21]$ & Trust in digital currency & $\begin{array}{l}\text { Trust } \\
\text { Theory }\end{array}$ & Survey & China \\
\hline$[22]$ & $\begin{array}{l}\text { The use of bitcoin in light of the } \\
\text { financial crisis }\end{array}$ & - & Survey & UK \\
\hline$[23]$ & $\begin{array}{l}\text { Consumers' adoption and use of } \\
\text { bitcoin and other virtual currencies }\end{array}$ & - & Survey & USA \\
\hline [24] & $\begin{array}{l}\text { Bitcoin, revelling user's hidden } \\
\text { intentions }\end{array}$ & - & Survey & Germany \\
\hline$[25]$ & $\begin{array}{l}\text { Digital currency's speculative } \\
\text { nature }\end{array}$ & - & Survey & Korea \\
\hline
\end{tabular}

\subsubsection{Other research}

In this category, authors used mixed method and other types of methodologies such as empirical analysis, SWOT, theoretical analysis and contemporaneous analysis to carry their research. In their research, they proposed a new notion named algorithmic authority for understanding the role of algorithms in human's daily life [26]. Algorithmic authority is defined as the legitimate control of algorithms to direct human action and to decide which information is considered true [26]. The study utilizes a mixed method of interview and survey data to gather and the information and generate the results. The findings indicate that bitcoin consumers prefer algorithmic authority to the convening authority institutions, which they feel as untrustworthy.

A group of researchers proposed a bitcoin adoption and pricing theoretical model, and then utilizes that model to carry out an empirical analysis [27]. Diversity of empirical techniques was used to draw inferences about bitcoin use cases and how they differ from different regions of the world. As a result, the theoretical model proposed emphasizes on the vital role played by frictions in adoption of bitcoin among consumers, ranging from the hazard of failure of a technology, to the fact that the value of the technology is affected by the adoption of other consumers (based on the exchange rate). Furthermore, the micro-level empirical analysis conducted also point out to the fact that aggregate adoption statistics about a new technology can be misleading: a lot of new adopters do not realize the usefulness of bitcoin as a technology on an on-going basis, other than for saving. Additionally, the analysis indicates that the adoption and usage of trends are somewhat localized, even though the main feature of the cryptocurrency technology is freeing from thirdparty involvement. Upcoming research may further discover the network structure of bitcoin and the process of how consumers interact with each other within the network.
In his research, the study performed an analysis of cryptocurrency, bitcoin and its future potential. The author conducted a SWOT analysis of bitcoin, which lighten some of the recent events and movements that could influence the bitcoin contribution to a change the economic architecture [1]. As stated by the author, cryptocurrencies are still in their beginning stages of adoption, and it is hard to say whether it will ever face a real mainstream utilization in the current world markets. There is a possibility that the future is holding a significant place for cryptocurrency as an alternative method of payment, and as if can be noticed that bitcoin is contributing in paving the way for those cryptocurrencies to flourish. Both [28] in their research study on the adoption of bitcoin as a digital currency through a digital transformation mentioned that the design of bitcoin and other cryptocurrencies has entered the financial payment network, offering an alternative to currencies to the current fiat currencies independently freeing from interference and control of the authorities. Nevertheless, consumers' adoption for bitcoin and other cryptocurrencies is still low due to some consumer's perception of them as a financial investment instead of a method of payment for daily purposes. On the other hand, although there is a huge limitation in payment acceptance by merchants, cryptocurrencies' consumers have the tendency to use them for payments, roughly in equal percentage compared to speculative investment.

The research paper addresses the existing situation of technology and skepticism concerning the upcoming buying power of current monies and the reason behind cryptocurrencies failure to obtain widespread adoption by providing a clarification based on network effects and switching costs mechanism [29]. To carry out the research, the author employed a sample mode for currency competition, network externalities, and switching costs towards an alternative view of ideal currency areas. The author concludes his research by stating that alongside the absence of important monetary instability or government support, cryptocurrencies are hardly to 
gain a widespread acceptance. Finally, the author believes that a successful transition needs widespread coordination to solve the network effects at play. Additionally, the costs of coordination are probably to rise as the pool of early adopters is filled up.

In the research about the blockchain technology and challenges hampering its adoption mentioned that despite the fact that blockchain has been gaining the attention whereby new applications utilizing the blockchain architecture are introduced [30]. Yet, majority of consumers are still hesitant to adopt blockchain as well as cryptocurrencies particularly. The majority of consumers are still having a lack of understanding the usefulness of the technology, which leads to lower rates of adoption [30]. As a result, the author believes that blockchain technology is a promising technology with big potential for nonfinancial application. Yet, the problem with its adoption is mainly presented by a lack of awareness and the level of understanding of the functionality of the technology. As for future directions, author is recommending increasing the level awareness among consumers regarding this technology. Another research study addresses the effect of social media on bitcoin performance made by [31]. In this research study, the authors start by examining the dynamic relationship between social media that consist of mixed signals from various consumers and systems, and the actual value of bitcoin. The results reveal that not all social media messages are created equally in terms of explaining the process of the adoption for new financial technologies. Furthermore, the research highlights the unpredicted status of the silent majority, so researchers should work to create algorithms that are able to dynamically select the most impactful social media consumers, not necessarily the most active ones.

Table 3 Other research

\begin{tabular}{|c|c|c|c|c|c|c|}
\hline \multicolumn{2}{|c|}{ Category } & \multirow[t]{2}{*}{ Paper } & Area of research & Model & Methodology used & \multirow{2}{*}{$\begin{array}{l}\text { Country } \\
\text { USA }\end{array}$} \\
\hline $\begin{array}{l}\text { Mixed } \\
\text { Method }\end{array}$ & [26] & & $\begin{array}{l}\text { Algorithmic authority, the case of } \\
\text { bitcoin }\end{array}$ & - & $\begin{array}{l}\text { Interview } \quad \& \\
\text { Survey }\end{array}$ & \\
\hline \multirow[t]{6}{*}{ Other } & [27] & & Bitcoin pricing, adoption, and usage & - & Empirical analysis & UK \\
\hline & [1] & & $\begin{array}{l}\text { An analysis of cryptocurrency, } \\
\text { bitcoin, and the future }\end{array}$ & - & SWOT & USA \\
\hline & [28] & & $\begin{array}{l}\begin{array}{l}\text { Adopting the bitcoin as a digital } \\
\text { currency } \\
\text { through } \\
\text { transformation }\end{array}\end{array}$ & - & $\begin{array}{l}\text { Theoretical } \\
\text { Analysis }\end{array}$ & $\begin{array}{l}\text { New } \\
\text { Zealand }\end{array}$ \\
\hline & [29] & & $\begin{array}{l}\text { Cryptocurrencies, network effects, } \\
\text { and switching costs }\end{array}$ & - & Empirical analysis & USA \\
\hline & [30] & & $\begin{array}{l}\text { Blockchain technology and its } \\
\text { challenges hampering its adoption }\end{array}$ & - & Empirical analysis & $\begin{array}{l}\text { South } \\
\text { Africa }\end{array}$ \\
\hline & [31] & & $\begin{array}{l}\text { The impact of social media on } \\
\text { bitcoin performance }\end{array}$ & - & $\begin{array}{l}\text { Contemporaneous } \\
\text { Analysis }\end{array}$ & USA \\
\hline
\end{tabular}

\section{Summary of cryptocurrency research} Tables 1, 2, 3 outline the type of research carried out in which (5) publications were categorized as a qualitative research, (13) publications were categorized as quantitative research, (1) was categorized as mixed method research and (8) categorized as others. Figure 2 below summarizes the categorized discussed above by highlighting the type of research conducted as well as the country and the year for each paper involved in this systematic literature review. 
Redhwan Al-Amri et al.

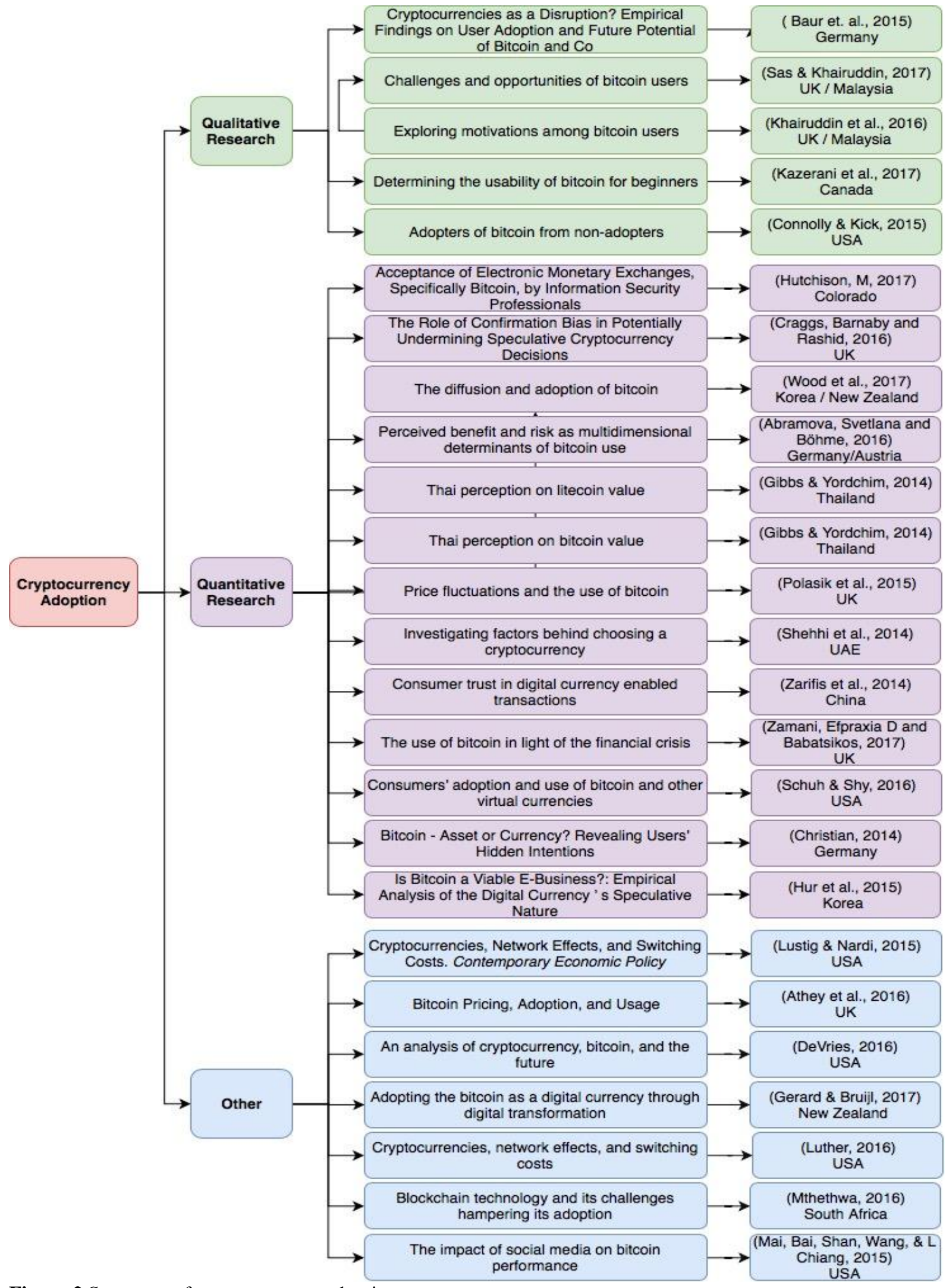

Figure 2 Summary of cryptocurrency adoption 


\section{Discussion and research gap}

Generally, there are two major research paradigms to guide the researchers, namely constructivism and positivism. Constructivist paradigm holds the assumption that researchers are allowed to develop subjective meanings from individuals' experiences towards certain issues in order to understand a certain phenomenon [32]. The qualitative research approach is usually associated with this research paradigm. Researchers can interact directly with the subjects in order for the researchers to interpret the meaning that the subject has about a phenomenon.

On the other hand, positivism is usually associated with quantitative researches that assume there is one true reality that can be discovered by means of rigorous empirical study [32]. Researchers in this paradigm view themselves as neutral observers where the outcome of the research is not influenced by their values, beliefs, and biases [33]. Therefore, in a positivist paradigm, researchers are expected to distant themselves from the research subject in order to ensure objectivity during the data collection and analysis phases [34].

In this systematic literature review, the first classification of this paper used the constructivist approach to conduct the study where the authors used to collect the data through interviews and analyze the data collected. On the other hand, it was noted that most of the research conducted in cryptocurrency adoption used the positivism approach where the authors performed surveys to collect the data from respondents and then analysis them to take their hypothesis. Apart from that, some authors used other approaches such as mix-methods to conduct their studies.

From this systematic literature review, we identified many research gaps in cryptocurrency adoption research that have the potential to be studied in the future. The methodologies employed to categorize those gaps are as follows. First, detecting the problems or limitations from the research papers included in this research. Second, recognizing issues that were highlighted by the authors as a future work.

The first gap is a lack of study on significant factors influencing the cryptocurrency adoption. As a technology that involved with financial sectors, it is vital to consider factors that significantly influence users' intention to adopt new technology. These factors include and not limited to risk, trust and security factors. When it comes to financial application, consumers always have a resistance to change, where in this situation; researchers should also consider awareness factors as a major player in
International Journal of Advanced Computer Research, Vol 9(44)

determining the main factors influencing the adoption of new technology. Furthermore, ease of use and usefulness have considered some of the major factors affecting the users' intention to adopt new technology. In addition, monetary instability, value formation as well as government support plays a great role in enhancing the adopting rate among user.

The second gap is the lack of technology adoption models used in addressing the issue of cryptocurrency adoption. Based on the SLR there is a lack of usage of technology adoption models by the researchers. Varieties of models are available that it can determine the factors that have significant influence towards the adoption of cryptocurrency. In addition, there is a lack of consideration of moderating factors that affect the acceptance and adoption rate of cryptocurrency such as subjective norms, social factors and facilitating conditions.

The third gap is regarding the sampling size, where in most of the researches conducted, sampling size is small and not covering a larger geographical location. There is a great need to extend the population to cover not only users' sides, but also banking sectors, stock brokerages and foreign currency exchange. Wider range participants' involvement is highly recommended to get accurate results and gain a deeper understanding of users' expectations from a new service. Furthermore, sampling method employed must cover both probability and nonprobability sampling.

The fourth gap is driven by the fact that only few papers address the adoption from human perspectives. Few papers address the users' perception towards using cryptocurrency as a new method of payment. Furthermore, research should extrapolate future bitcoin diffusion and adoption and survey companies directly as to why they adopted cryptocurrency, which will increase the overall understanding of how an innovation proceeds through the adoption lifecycle. At the same time, it is highly recommended to work on merchants' acceptance and adoption for cryptocurrency as it plays a vital factor in influencing others to adopt it. The final gap is the lack of comprehensive highquality research paper on cryptocurrency adoption. Most of the papers found were not comprehensive in the sense of analysis in addressing the issue of adoption among consumers. There is, therefore, a need for comprehensive high-quality publications on cryptocurrency adoption combined with great contribution.

\section{Conclusion and future work}

This paper addresses four research questions as mentioned above. The first question regarding to 
Redhwan Al-Amri et al.

topics that have been addressed in cryptocurrency, and that was answered by gathering related papers from scientific databases. The second question was regarding the models that have been used to carry out cryptocurrency adoption, and that was answered by reviewing the methodology used in all the relevant papers. The third and fourth questions were regarding the current gaps in cryptocurrency adoption, and the future directions for the adoption of cryptocurrency research, were answered by performing a systematic literature review.

The evidence presented from the findings shows that researchers have utilized several methods of data gathering such as qualitative, quantitative, mixed method and others while conducting the cryptocurrency adoption research phenomenon. Studies have also contributed to understanding the cryptocurrency adoption and its state of research. The findings reveal that researchers resume exploring the emerging cryptocurrency adoption phenomenon. Nonetheless, there is still a potential for future research.

Cryptocurrency runs based on blockchain technology, which is a decentralized platform, where transactions are stored in public ledger, transparent to participants. The Blockchain's goal is to provide the users with anonymity, security, privacy, and transparency. Nevertheless, cryptocurrencies it still has some adoption challenges and limitations that need to be addressed. Solid research needs to be performed to address the user attitudes and behavior towards adopting cryptocurrency from different perspectives.

To understand where the current research on cryptocurrency adoption positions itself, we decided to perform a systematic literature review of all relevant research. The goal of this systematic literature review was to identify the current-status cryptocurrency adoption research topics. We excluded papers from the security and legal issues or purely technical aspects of cryptocurrencies and included only the acceptance and adoption papers. We extracted and analyzed 25 primary papers from scientific databases. We provide recommendations on future research directions of cryptocurrency adoption based on the current research status as follows:

\section{Identify factors that significantly influence users' intention to adopt cryptocurrency}

This involves factors from human and security perspectives. From the human perspectives, it's vital to include factors such as ease of use, usefulness, social factors and facilitating conditions. In addition, it is also important to consider moderating factors such as subjective norms, monetary instability, value formation as well as government support which plays a great role in enhancing the adopting rate among user. On the other hand, from a security perspective as cryptocurrency is involved with financial matters, it is necessary to address security factors such as perceived risk that includes (security risk, financial risk, information risk, time risk, social risk, performance risk and psychological risk), Perceived trust, perceived privacy and awareness.

\section{Conduct more studies on technology acceptance and adoption models}

Most of the current research on the cryptocurrency is focusing on TAM as a model to address cryptocurrency adoption. The issue with TAM is that it does not look at the adoption for financial perspective and it does not consider the financial risk. Addressing other acceptance and adoption model is highly recommended in such technology as it involves financial sectors. Models such as (Diffusion of Innovation, Theory of Planned behavior, Theory of Reasoned Action, Unified Theory of Acceptance and Use of Technology and Technology-Task Fit) are highly recommended to be considered in addressing the cryptocurrency adoption.

Focusing more in the methodology utilized in gathering the data

The systematic literature review conducted shows a lack of methodology used to gather the data. Mixed method is rarely used in addressing the cryptocurrency adoption and when it comes to either qualitative or quantitative method there is always a gap in either the sampling size or population, which highlights the need for a better study that covers the topic of cryptocurrency in depth by employing a good methodology for data collection.

\section{Studying the adoption from the perspective of consumers and merchants}

There is a vital need to address the factors influencing the adoption for both consumers and merchants to have an overall understanding of the whole cycle of cryptocurrency adoption. Studies should address consumers from all aspects as well as merchants, including banking sectors, stock brokerages and foreign currency exchange.

The needs of high impact journals addressing the cryptocurrency adoption

As reviewed, none of the work addressing cryptocurrency have been published in high impact journals, which calls for the attention to conduct such 
studies in greater journals and ensure a great contribution out of the research papers

\section{Acknowledgment}

This work was supported by the Ministry of Higher Education, Malaysia, through FRGS Research Grant 13257.

\section{Conflicts of interest}

The authors have no conflicts of interest to declare.

\section{References}

[1] DeVries PD. An analysis of cryptocurrency, bitcoin, and the future. International Journal of Business Management and Commerce. 2016; 1(2):1-9.

[2] Sas C, Khairuddin IE. Design for trust: an exploration of the challenges and opportunities of bitcoin users. In proceedings of the chi conference on human factors in computing systems 2017 (pp. 6499-510). ACM.

[3] Murphy EV, Murphy MM, Seitzinger MV. Bitcoin: questions, answers, and analysis of legal issues. Library of Congress, Congressional Research Service.2015.

[4] Fung B, Halaburda H. Understanding platform-based digital currencies. Bank of Canada Review. 2014; 2014(Spring):12-20.

[5] Baur AW, Bühler J, Bick M, Bonorden CS. Cryptocurrencies as a disruption? empirical findings on user adoption and future potential of bitcoin and co. In conference on e-business, e-services and e-society 2015 (pp. 63-80). Springer, Cham.

[6] Kazerani A, Rosati D, Lesser B. Determining the usability of bitcoin for beginners using change tip and coinbase. In proceedings of the ACM international conference on the design of communication 2017 (p. 5). ACM.

[7] Nakamoto S. Bitcoin: a peer-to-peer electronic cash system. 2008.

[8] Yli-Huumo J, Ko D, Choi S, Park S, Smolander K. Where is current research on blockchain technology?a systematic review. PloS one. 2016; 11(10):1-27.

[9] Keele S. Guidelines for performing systematic literature reviews in software engineering. Technical Report, Ver. 2.3 EBSE Technical Report. EBSE; 2007.

[10] Petersen K, Feldt R, Mujtaba S, Mattsson M. Systematic mapping studies in software engineering. In Ease 2008 (pp. 68-77).

[11] Janssen M, Mäntymäki M, Hidders J, Klievink B, Lamersdorf W, Van Loenen B, et al. Open and big data management and innovation. 14th IFIP WG 6.11 conference on e-business, e-services, and e-society, I3E 2015, Delft, the Netherlands, Proceedings. Springer.

[12] Khairuddin I, Sas C, Clinch S, Davies N. Exploring motivations among bitcoin users. CHI'16 Extended Abstracts on Human Factors in Computing Systems. 2016:2872-8.

[13] Connolly A, Kick A. What differentiates early organization adopters of bitcoin from non-adopters? 2015.
International Journal of Advanced Computer Research, Vol 9(44)

[14] Hutchison M. Acceptance of electronic monetary exchanges, specifically bitcoin, by information security professionals: a quantitative study using the unified theory of acceptance and use of technology (UTAUT) Model. (Doctoral Dissertation, Colorado Technical University).2017.

[15] Craggs B, Rashid A. Poster: the role of confirmation bias in potentially undermining speculative cryptocurrency decisions. In IEEE European Symposium on Security and Privacy 2016.

[16] Wood, J., Jang, H., Lenskiy, A., \& Khan, G. The diffusion and adoption of bitcoin: a practical survey for business. International Business Management, 11(6):1278-88.

[17] Abramova S, Böhme R. Perceived benefit and risk as multidimensional determinants of bitcoin use: a quantitative exploratory study. ICIS 2016.

[18] Gibbs T, Yordchim S. Thai perception on Litecoin value. International Journal of Social, Behavioral, Educational, Economic, Business and Industrial Engineering. 2014; 8(8):2613-5.

[19] Polasik M, Piotrowska AI, Wisniewski TP, Kotkowski $\mathrm{R}$, Lightfoot $\mathrm{G}$. Price fluctuations and the use of Bitcoin: an empirical inquiry. International Journal of Electronic Commerce. 2015; 20(1):9-49.

[20] Al Shehhi A, Oudah M, Aung Z. Investigating factors behind choosing a cryptocurrency. In international conference on industrial engineering and engineering management 2014 (pp. 1443-7). IEEE.

[21] Zarifis A, Efthymiou L, Cheng X, Demetriou S. Consumer trust in digital currency enabled transactions. In international conference on business information systems 2014 (pp. 241-54). Springer, Cham.

[22] Zamani ED, Babatsikos I. The use of bitcoins in light of the financial crisis: the case of Greece. In the mediterranean conference on information systems 2017 Genoa, Italy.

[23] Schuh S, Shy O. US consumers' adoption and use of bitcoin and other virtual currencies. In DeNederlandsche bank, conference entitled "retail payments: mapping out the road ahead 2016.

[24] Glaser F, Zimmermann K, Haferkorn M, Weber MC, Siering M. Bitcoin-asset or currency? revealing users hidden intentions. Revealing Users Hidden Intentions. ECIS. 2014.

[25] Hur Y, Jeon S, Yoo B. Is bitcoin a viable e-business?. empirical analysis of the digital currency's speculative nature ICIS 2015.

[26] Lustig C, Nardi B. Algorithmic authority: the case of Bitcoin. In hawaii international conference on system sciences 2015 (pp. 743-52). IEEE.

[27] Athey S, Parashkevov I, Sarukkai V, Xia J. Bitcoin pricing, adoption, and usage: theory and evidence. 2016.

[28] Bruijl GH. Adopting bitcoin as a digital currency through digital transformation. 2017.

[29] Luther WJ. Cryptocurrencies, network effects, and switching costs. Contemporary Economic Policy. 2016; 34(3):553-71.

[30] Mthethwa S. The analysis of the blockchain technology and challenges hampering its adoption. 
World Academy of Science, Engineering and Technology, International Science Index, Computer and Information Engineering. 2016; 10(12):1937-48.

[31] Mai F, Bai Q, Shan Z, Wang X, Chiang R. From bitcoin to big coin: the impacts of social media on bitcoin performance. SSRN Electronic Journal. 2015.

[32] Creswell JW, Creswell JD. Research design: qualitative, quantitative, and mixed methods approaches. Sage Publications; 2017.

[33] Guba EG, Lincoln YS. Competing paradigms in qualitative research. Handbook of Qualitative Research. 1994:105-17.

[34] Bell E, Bryman A, Harley B. Business research methods. Oxford University Press; 2018.

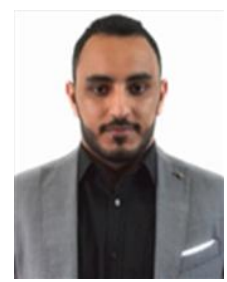

Redhwan Al-Amri received the Bachelor degree in Computing from Staffordshire University, Malaysia, in 2011 and the Master degree in Computer Science (Information Assurance) from Universiti Teknologi Malaysia (UTM) in 2017, Malaysia. He is currently pursuing the Ph.D. degree in Computer Sceince at Taylor's University, Malaysia. His research interests include Human Computer Interaction, Computer Security, Blockchain, Cryptography and Ineternet of things.

Email:

Redhwanmohammedabdullahalamri@sd.taylors.edu.my

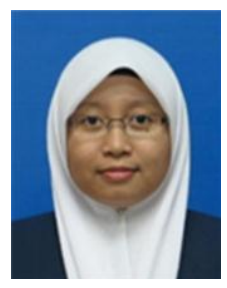

Nur Haryani Zakaria received her $\mathrm{PhD}$ in Computing Science from Newcastle University, United Kingdom. She is currently a Senior Lecturer at School of Computing, College of Arts and Sciences, and also the Deputy Dean of Awang Had Salleh Graduate School, Universiti Utara Malaysia. Her research interests include Network Security, Information Security, Usable Security, Password Compliance and Single Sign-On. She received a Master of Science in Computer Science from Universiti Teknologi Malaysia.

Email: haryani@uum.edu.my

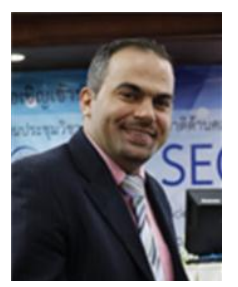

Adib Habbal (SM'15) is a Professor (Associate) of Computer Engineering at Karabuk University, Turkey. Before joining the Karabuk University in 2019, he was a senior lecturer at Universiti Utara Malaysia (ten years) and head of InterNetWorks Research Platform (three years). He also served as IEEE UUM Student Branch Founding Counselor and Executive Council Member of the Internet Society Malaysia Chapter. Dr. Habbal received his Ph.D. degree in Computer Science (specializing in Networked Computing) from Universiti Utara Malaysia. Dr. Habbal has received a number of recognitions from Universiti Utara Malaysia (UUM) for his outstanding educational and research activities including the Excellent Service Award (2010), Best Research Award (2014), Prolific Writer Award (2016) and many others. He has been the recipient of an Internet Society Fellowship to the Internet Engineering Task Force (IETF), an IEEE Malaysia Section Best Volunteer Award, and an AsiaPacific Advanced Network (APAN) Fellowship. Dr. Habbal is a senior member of the Institute of Electrical and Electronic Engineers (IEEE). Dr. Habbal's research projects have been funded by several organizations, including IEEE R10, IEEE Malaysia Section, Internet society, Malaysian Ministry of Higher Education, Universiti Utara Malaysia and others. He has over 80 publications in journals and conference proceedings in the areas of Future Internet, and performance evaluation. His professional experience includes being a speaker at a number of renowned research conferences and technical meetings such as IEEE, internet2, APAN, and APRICOT, an editor for the top tier and refereed journals, a technical program committee for IEEE conferences on computing networks as well as an examiner for postgraduate scholars in his research areas. His research interests include Future Internet Protocols and Architecture, 5Th Generation Mobile Networks, as well as Blockchain Technology and Digital Trust.

Email: adibhabbal@karabuk.edu.tr

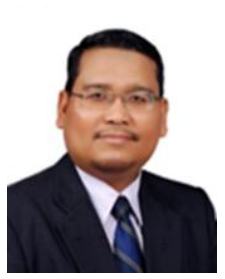

Professor Dr. Suhaidi Hassan received the bachelor's degree in computer science from the State University of New York at Binghamton, New York, the master's degree in information science (telecommunication/networks) from the University of Pittsburgh in Pennsylvania, and Ph.D. in computing (computer networks) from the University of Leeds in United Kingdom. He is a tenure track professor of computing network and the founding chair of the InterNetWorks Research Laboratory at the School of Computing, Universiti Utara Malaysia (UUM). Prof. Hassan has held various academic, administrative positions, including the Assistant Vice Chancellor of UUM College of Arts and Sciences, Dean of the UUM Faculty of Information Technology, and the Deputy Director of Research at the UUM Centre for Research and Consultancy. He also served as a visiting professor at national and international universities. He is also a founding member and the current President of the Internet Society Malaysia, as well as the Internet Society Fellow alumnus to the Internet Engineering Task Force (IETF). He has authored and co-authored over 250 refereed technical publications and successfully supervised $26 \mathrm{Ph} . \mathrm{D}$. scholars in his research area of computer and communication networks. He was a recipient of the Swiss WKD Foundation's Young Scientist Fellowship Award of the World Knowledge Dialogue, Crans-Montana, Switzerland, in 2006. In the same year, he led a task force for the establishment of the International Telecommunication Union (ITU)-UUM Asia-Pacific Centre of Excellence for Rural ICT Development, a human resource development initiative of the ITU, which serves as the focal point for rural ICT development initiatives across Asia-Pacific region. In addition to being the invited speaker at numerous research conferences and technical meetings such as the IETF and IEEE meetings, he also participates in international public fora, such as ICANN 
meetings and the Internet Governance Forums. He has served as editor, reviewer, and referee for journals and conferences, as well as an examiner for over 100 doctoral and postgraduate scholars in his research areas. Prof. Hassan is also a founding member of the IHL Distributed Ledger Technologies Consortium (IDLTC), a blockchain consortium established under the purview of the Malaysian Ministry of Education, and a founding member of the Internet Society (Global) Blockchain Special Interest Group.

Email: suhaidi@uum.edu.my 